\title{
Lú Pires e a arte da gravura em metal
}

Que difícil tarefa a de escrever sobre si mesmo, o que está por trás da obra, o artista, o criador. Ultimamente escrever tem sido o meio que encontrei para me expressar. Agora o desafio é maior, me foi feito um pedido, falar de Lú Pires e da arte da gravura em metal. Não vai ser fácil, vem milhões de coisas para contar e tenho que ser criteriosa na escolha. Terei que remexer nas gavetas da memória, fazendo um recorrido pela minha história. Então vou começar de lá quando ainda era Maria de Lourdes Pires, nascida em uma família de oito irmãos, quatro homens e cinco mulheres, sou a mais nova delas.

Nasci em um sítio, cercado de muito verde, quando ainda não tinha luz elétrica, mas a recordação que ficou deste tempo é a melhor que tenho da minha infância. Tive uma educação bastante rígida, e por ser a mais nova era bem cuidada e vigiada. Eu já me destacava pela forma inquieta de ser. Tinha uma curiosidade e uma ingenuidade fora do normal, que muitas vezes incomodavam os meus irmãos. Os meus pais sempre foram muito amorosos, sou fruto de uma relação de amor. Homem muito sábio, meu pai, na sua simplicidade sempre nos ensinava e orientava com seus ditados e com sua experiência de vida. Até hoje quando estou com dúvida em algo, sempre lhe faço uma consulta. Foi desta forma simples e sincera que me educou a ser uma pessoa verdadeira e de princípios.

A minha mãe era uma mulher maravilhosa, tinha lindos olhos azuis e um jeito sereno de ser, sempre fui a sua preferida e protegida, os meus irmãos morriam de ciúmes 


\section{A $\begin{gathered}\text { Revista } \\ \text { APOTHEKE }\end{gathered}$}

desta relação. Morreu em 2007, com 84 anos, foi muito difícil para mim, pois na época estava com uma exposição marcada e tinha que terminar uma edição de gravuras, consegui terminar, mas o meu coração ficou arrasado com a perda. Descobri que o coração maior, aquele que nos guia e nos protege no mundo é o de mãe, e sem ele nos sentimos desorientados.

Com 15 anos, deixei a minha família e vim estudar em Florianópolis, onde estou até hoje.

Enfim, este é um pequeno relato pois se realmente fosse me detalhar teria que escrever muitas páginas porque a história é longa. Agora sigo com o caminho da arte.

\section{Gravura}

Tudo começou em 1991, quando fui morar em Cuba/ Havana, na época casada com o escritor Renato Tapado que tinha sido convidado para trabalhar em uma editora.

Ao chegar em Cuba, a primeira coisa que fiz foi conhecer o "Taller de Gráfica de Havana", um grande ateliê de gravura. Fiquei encantada, com muitas prensas e gravadores trabalhando, queria fazer parte daquele grupo. Assim que, por meio da editora, consegui um convite para participar como artista convidada, que (responsabilidade!), pois recém tinha começado a fazer litografia no Centro Integrado de Cultura/ Florianópolis.

No começo me senti bastante inibida ao lado de grandes mestres da gravura Cubana. Mas eles, na sua simplicidade, foram me deixando ficar. Até que um dia conheci um artista cubano muito especial: Angelo Alfaro, professor de gravura em metal no Instituto Superior de Arte de Havana. Falei do meu interesse em aprender a técnica de gravura em metal e ele prontamente me fez o convite para ser sua aluna. Foi 


\section{Revista
APOTHEKE}

assim que encontrei o caminho em direção à arte da gravura em metal.

Alfaro foi um grande mestre, com ele descobri a minha grande paixão, aquela que todo aluno quando está pronto quer encontrar. Me deu placas e ferramentas, porque em Cuba não tinha onde comprar, os alunos não compravam, eles recebiam os materiais de forma gratuita do governo.

Fiquei seis meses indo ao Instituto e também tive contato com outros professores: um que era mestre na técnica da maneira negra, e com ele que aprendi a arte de limpar bem uma placa para conseguir o preto mais puro e o branco com muita luz. Essa experiência nesse espaço foi muito rica, com arte por todos os lados, e uma arquitetura magnífica feita especialmente para aquele lugar.

Terminei o aprendizado da arte de gravar em metal e voltei ao "Taller de Gráfica de Havana", mas agora sabendo - que queria. Abandonei a litografia, consegui uma prensa pequena e nela eu passava todas as manhãs imprimindo as gravuras, não precisava de um impressor, queria aprender todas as etapas que envolvem o processo da gravura em metal. Ter estado nesse ateliê, com tantos outros gravadores, foi muito importante, aprendi muito, e curiosa ficava de olho em cada detalhe, fortalecendo a cada dia a paixão pela gravura dentro de mim. Fiz muitos amigos, vi muitas gravuras... e trabalhei muito para chegar onde cheguei.

Ao final de um ano em Cuba, já tinha uma série de gravuras e consegui fazer a minha primeira exposição, "Marcas" (1992), na galeria do Complexo Yara, em Havana. Também fui selecionada em um Salão de Arte "Comemorativo dos 30 anos de gravura do Museu Nacional de Cuba" e uma exposição coletiva de pequeno formato, Correio 


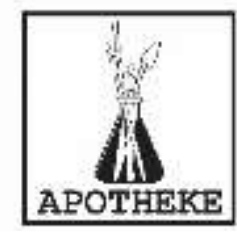

\section{Revista}

APOTHEKE

Internacional de pequena estampa (CIPE), na "IV Bienal de Havana" .

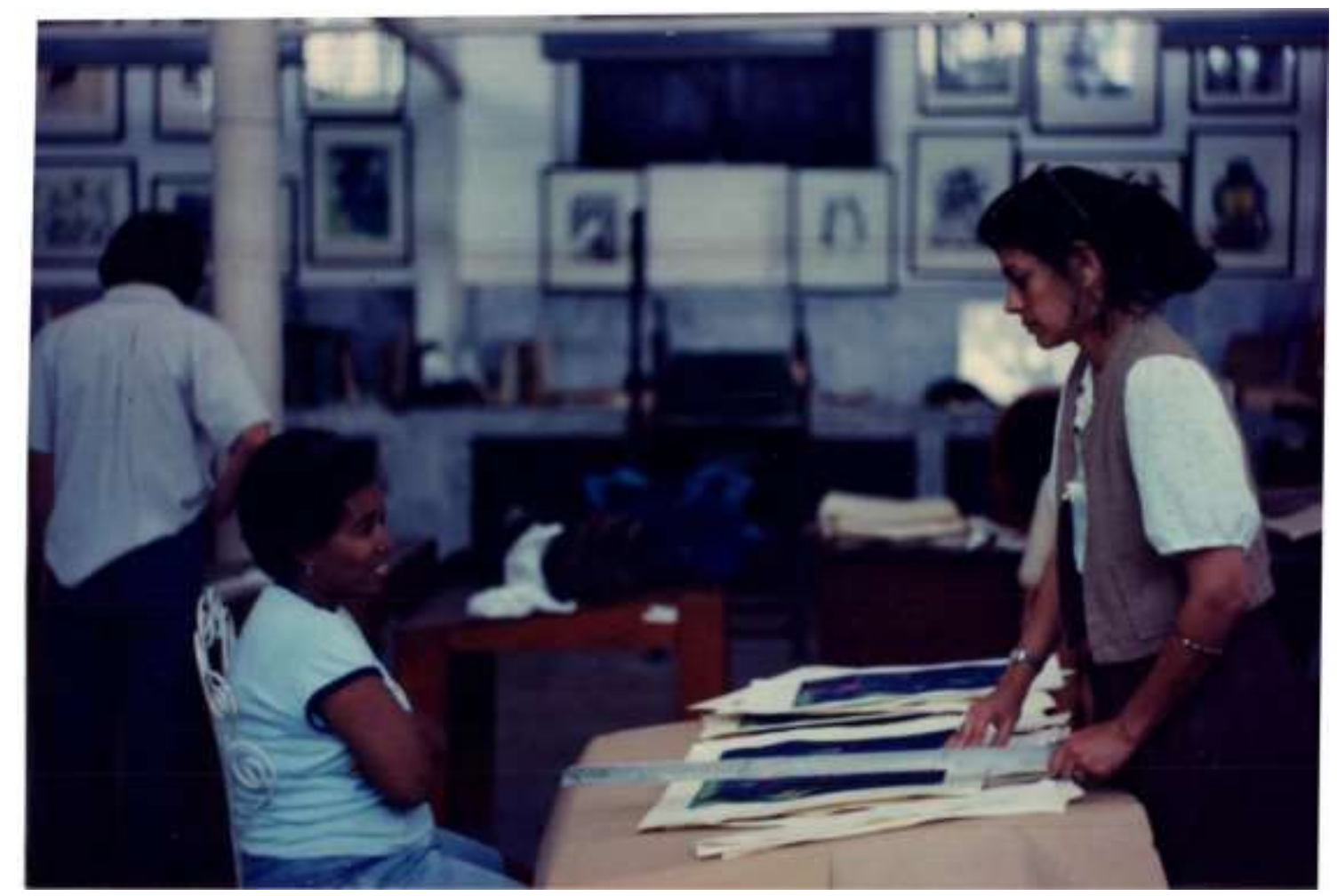

Taller de Gráfica de Havana - duas amigas gravadoras

\section{Técnica}

Em Cuba, tive a oportunidade de aprender todos os procedimentos técnicos que envolvem a gravura em metal. A técnica com a qual me identifiquei foi a ponta seca e maneira negra, pela forte relação que estabeleço com a matéria/matriz, além de não necessitar usar o ácido que é muito tóxico e pela liberdade que esta técnica oferece, podendo ser trabalhada em qualquer espaço.

Os meus primeiros trabalhos foram uma mistura das duas técnicas, a maneira negra pelos negros puros que conseguia e a ponta seca pelas linhas e tramas que com a força da incisão se complementavam.

De volta, montei um pequeno ateliê em minha casa, com uma prensa que um amigo me emprestou. Mas o querer ousar 


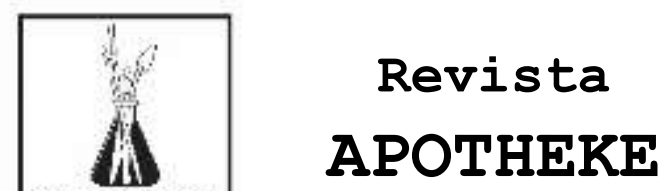

era grande e assim tive vontade de produzir gravuras com um formato maior, como grandes janelas.

Para realizar essas gravuras, tive que fazer placas do tamanho máximo permitido pela prensa. Elaborei um projeto de exposição, "Outono", para um edital de artes plásticas estadual e fui selecionada. Comecei o desafio. Agora, para realizar as gravuras, precisava aumentar o meu gesto de encontro a esta matéria, queria as texturas e os relevos que somente se consegue com a mordida forte do ácido na placa.

Assim, tive a ideia de usar a furadeira e a aventura começou. Tinha encontrado a minha ferramenta, aquela que aumentaria o meu gesto, aquela que me daria a força para penetrar fundo neste metal, aquela que junto com a minha dança iria tão longe, criando relevos e texturas como uma água forte, fazendo com que as pessoas não acreditassem se tratar de uma ponta-seca.

Depois da furadeira, encontrei o carborundum, que veio complementar a ferramenta que estava faltando para formar os grandes espaços negros do meu trabalho. Esta técnica aprendi com uma artista brasileira em um "Festival Latino Americano de Gravura" que aconteceu na Argentina Resistência Chaco, ela também era muito usada pelo Miró. o carborundum é um pó de lixa que se usa na limpeza da pedra de litografia, ele é aplicado na chapa com uma cola chamada poxipol. Estas duas técnicas hoje são a base do meu trabalho.

\section{Exposições}

A primeira exposição "Outono" (1995), foi a minha consagração como gravadora, ganhei o meu primeiro prêmio no "Salão Nacional Victor Meirelles". A segunda exposição foi "Caminhos" (1997), as gravuras foram feitas na Argentina, 


\section{A Revista}

levei a minha prensa e lá dei continuidade a minha aventura no metal, os negros foram ganhando novas tonalidades, vermelho, ocre e amarelo e verdes escuros. Fiz uma série de 30 gravuras para a exposição que seria realizada no museu Victor Meirelles.

Em 1999, me divorciei, e comecei o meu projeto para uma nova casa, Casa- Ateliê, um espaço criado com o objetivo não somente de ser um espaço de criação, mas também um espaço aberto para outros eventos, tais como: exposições, oficinas, workshops, encontros etc.

Em 2002, tive que me superar mais uma vez, o prazo era curto e queria realizar novos trabalhos, peguei licença do meu trabalho e me isolei por dois meses, 30 gravuras, a matéria já é obra, obra objeto, uma escultura; nascia a exposição "Detrás do Silêncio". Com estas gravuras me superei, pois a matriz acabada era uma obra única, o papel era somente a sua certidão de nascimento, fiquei feliz com - resultado.

Em 2003, fui convidada pela Fundação Badesc para uma exposição e, como não tinha tempo para produzir novas gravuras, realizei a mesma exposição do museu só que com um novo tema, "Corpo Único", onde a matriz seria exposta como obra. A exposição teve uma repercussão que me surpreendeu, pois as pessoas queriam comprar as matrizes, mas elas não estavam à venda.

Já em 2007, veio a exposição, a cor na gravura em metal, onde me desafiei com o uso das cores. A pintura estava presente na matriz. Além da incisão, a cor era parte integrante para conclusão da forma. Não fiz uma edição, somente uma prova de estado na cor preta, e uma prova do artista. Depois desta exposição houve um período de hibernação (2007 - 2012) para uma criação individual, considero como um espaço em branco na minha vida como 


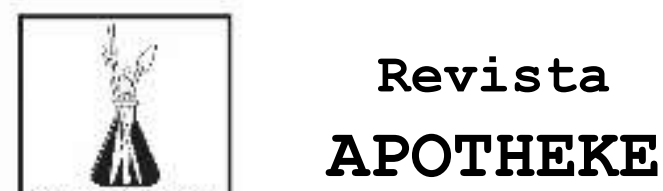

gravadora, mas como artista, me dediquei ao trabalho de Gestão de Arte Pública no Instituto de Planejamento Urbano de Florianópolis (IPUF), administrando e coordenando os trabalhos da Comissão Municipal de Arte Pública (COMAP) comissão que julga e aprova as obras de arte para as edificações e espaços públicos.

Hoje, Florianópolis é pioneira em ter uma lei vinculada ao novo Plano Diretor da cidade. Isso foi conseguido com o resultado dos três seminários realizados com a classe artística, estudantes e público em geral. O trabalho como mediadora desse processo, tem sido de muita importância tanto para mim como para toda a classe artística que se beneficia da lei. Agora, depois desta hibernação, estou retornando e vamos ver o que vai sair... mistério.

\section{4}

Começo um novo ciclo, tenho 52 anos, a maturidade é parte de mim, tento entender o tempo, as horas vazias nas quais não sou produtiva, simplesmente sou uma mulher comum; já não me diferencio, sou igual a todo mundo. Quem sou eu? Esta é a pergunta que me faço o tempo inteiro...

O ano passado fiquei duas semanas em uma residência artística em Córdoba/ Argentina com mais oito gravadores de Florianópolis. Tive que me desafiar depois de tanto tempo longe de tudo, penso que devagar vou retornando.

E a arte, onde fica no meio disso tudo?

Recentemente participei de uma mostra coletiva de gravura e emoldurei quatro trabalhos, desses quatro, uma gravura era de 2003, "Detrás do Silêncio", gravura que considero a minha "obra prima", com ela consegui atingir aquilo que todo artista almeja, que é, ir além da técnica, se superar. Tanto que com ela fui selecionada em uma Bienal 


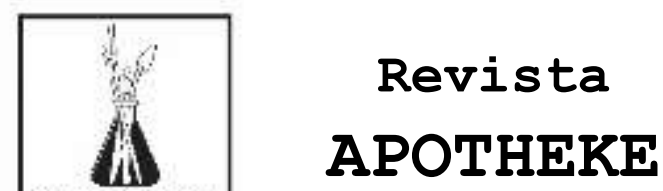

Internacional de Gravura (Ourense, na Espanha), considerada muito importante, foi a minha consagração como gravadora.

Agora, depois de 10 anos, a coloco na parede e me pego observando. Quando olho a forma que criei, fico intrigada e me pergunto: quem está do outro lado? E me assusto, vejo um mundo diferente do meu ali, naquele quadro existe um lugar misterioso, como um grande terreno baldio, um território desconhecido. Quando olho para a gravura me sinto arrastada para dentro dela, é como entrar na toca do coelho da Alice ou através do espelho, me incomoda essa possibilidade de ser espectadora de minha própria criação, que já não me pertence, é do mundo. Ali no meio dela existe uma marca, a marca de uma fechadura, e eu sou a chave de todo esse mistério que a envolve. Ao mesmo tempo, me sinto longe daquele lugar que criei, mas no momento a única coisa que de verdade me liga a este mundo é a criação e o fato de ser ainda uma artista, que com esta gravura, me surpreendo e me revela. Agora estou com medo de não conseguir abrir aquela porta que está ali à minha espera...

Lú Pires, manhã de 18 de julho de 2014. Exposição "A cor na gravura em metal"

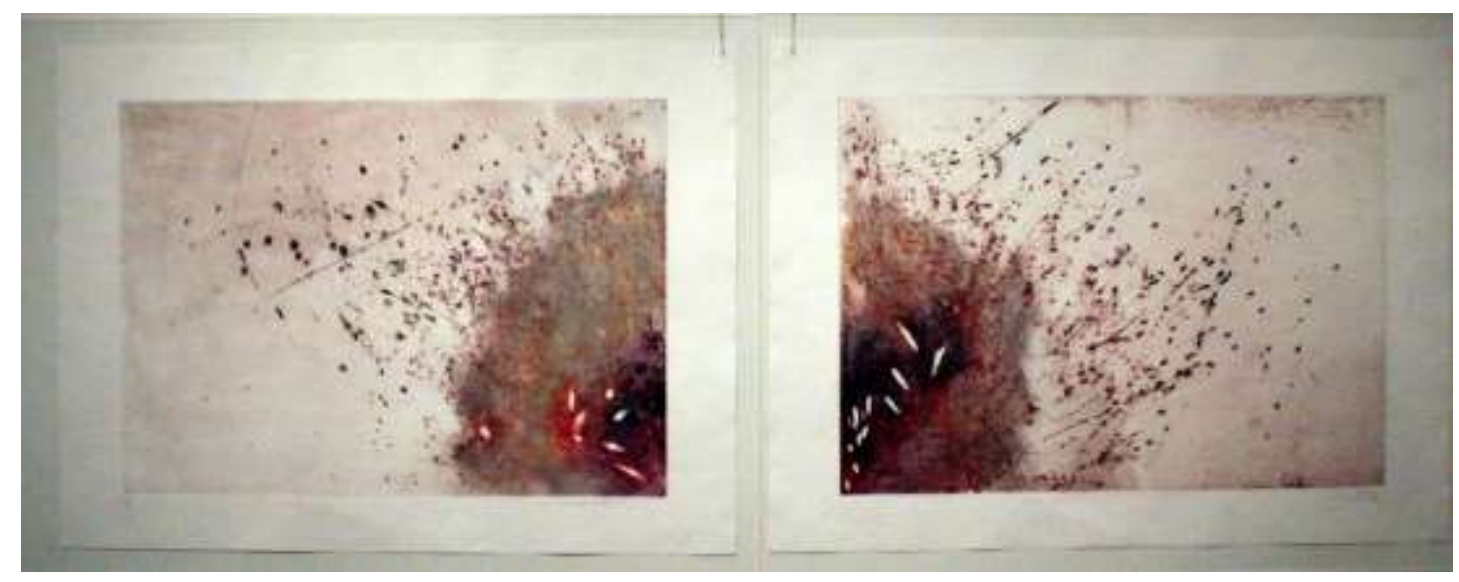

Exposição "Corpo único" 


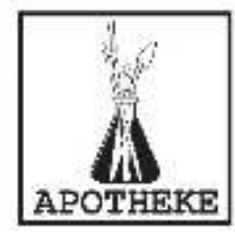

Revista

APOTHEKE

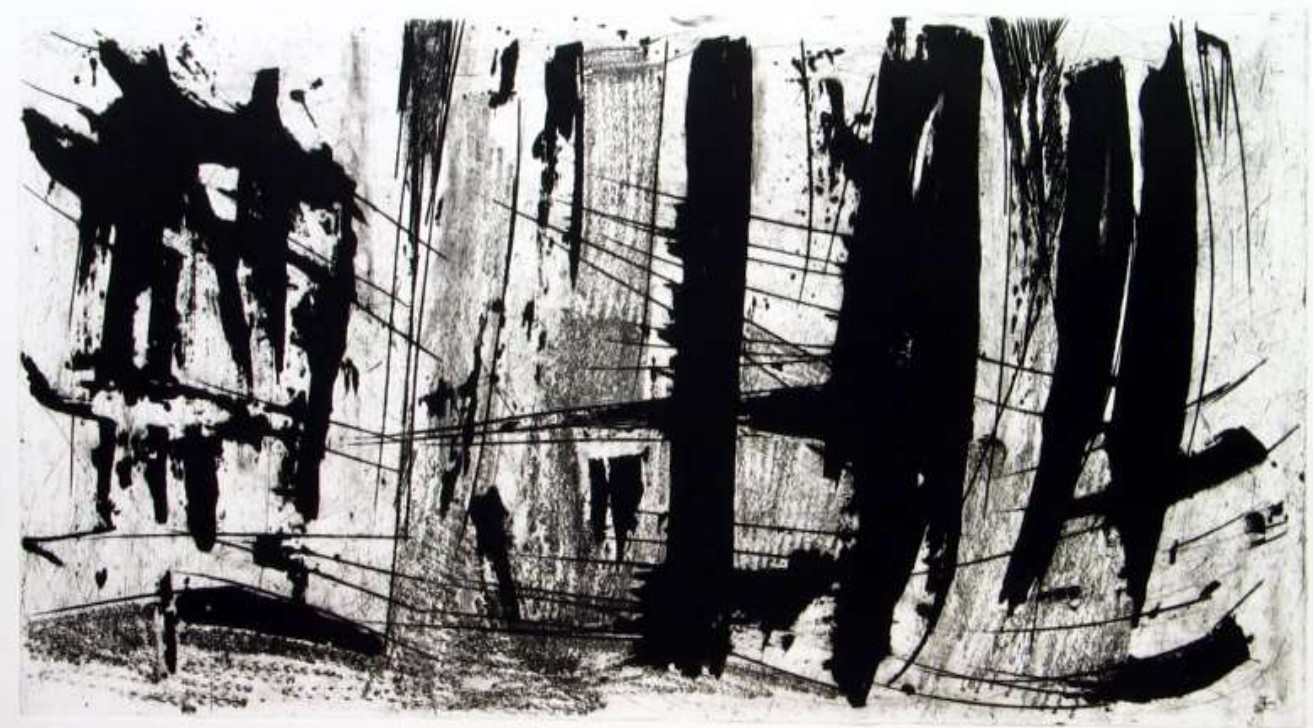

Gravura

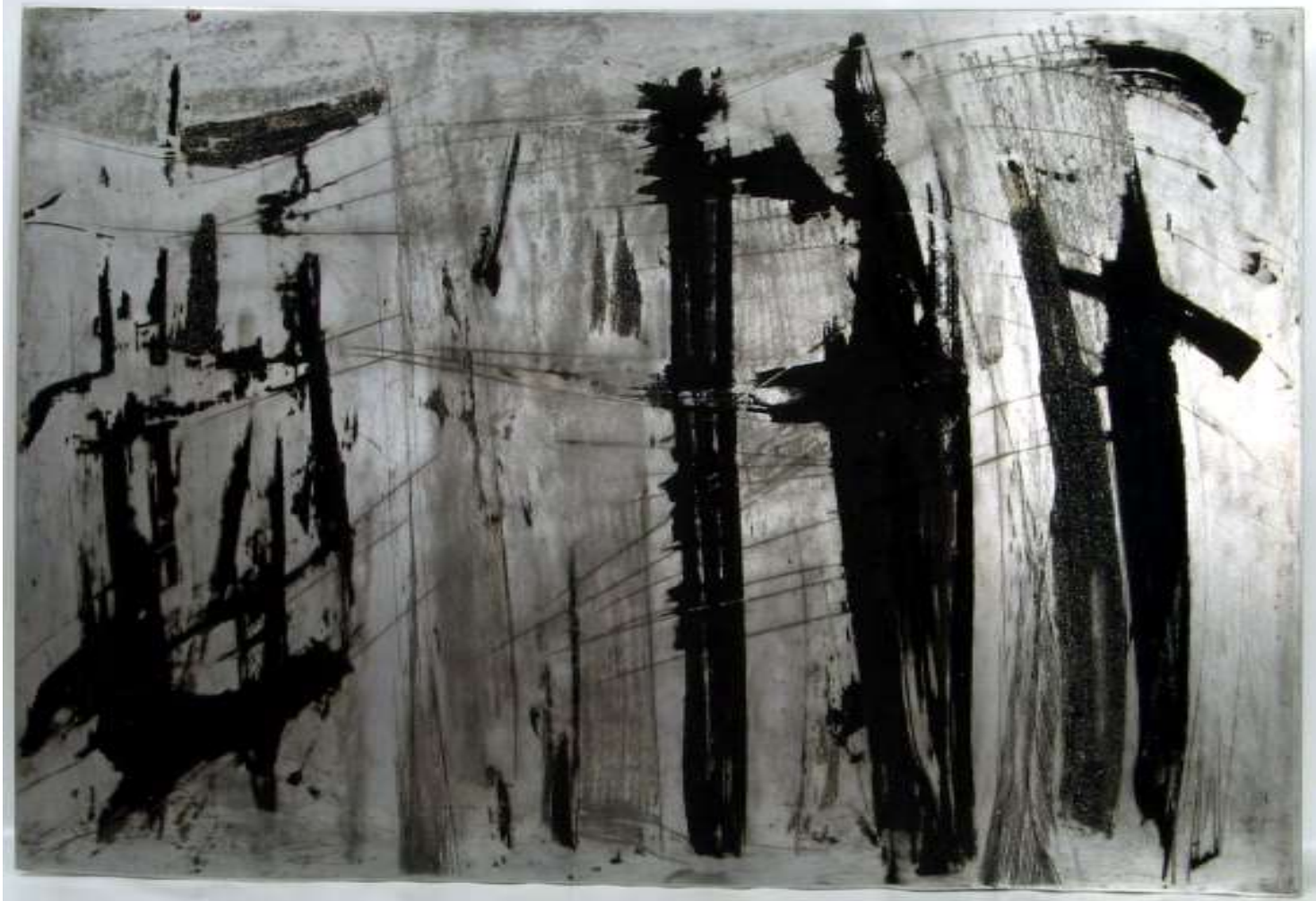

Matriz 


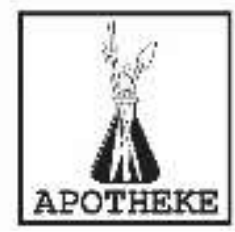

Revista

APOTHEKE

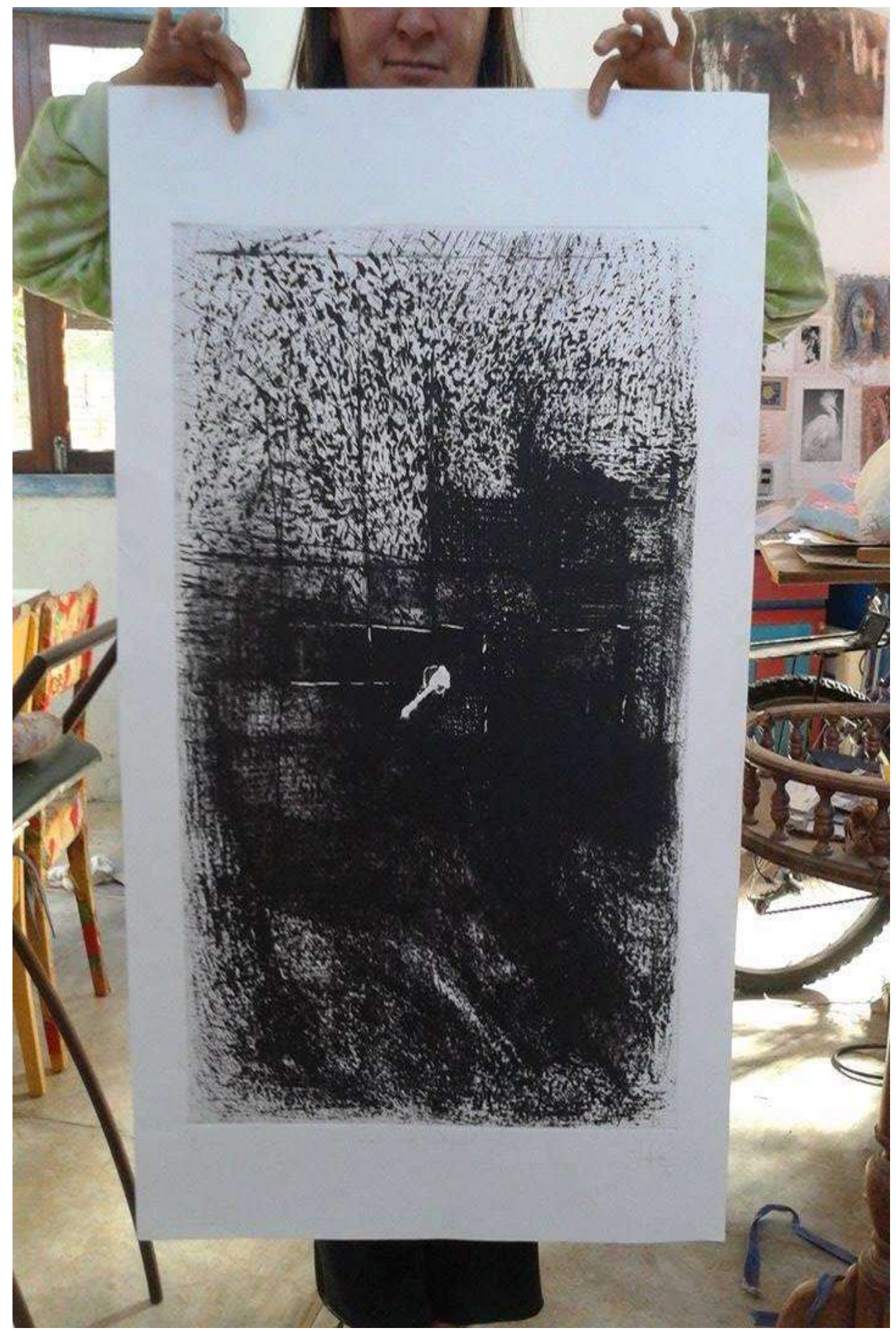

A cor na gravura em metal 


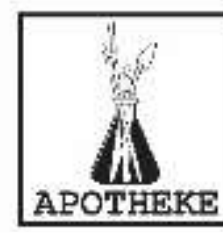

Revista

APOTHEKE
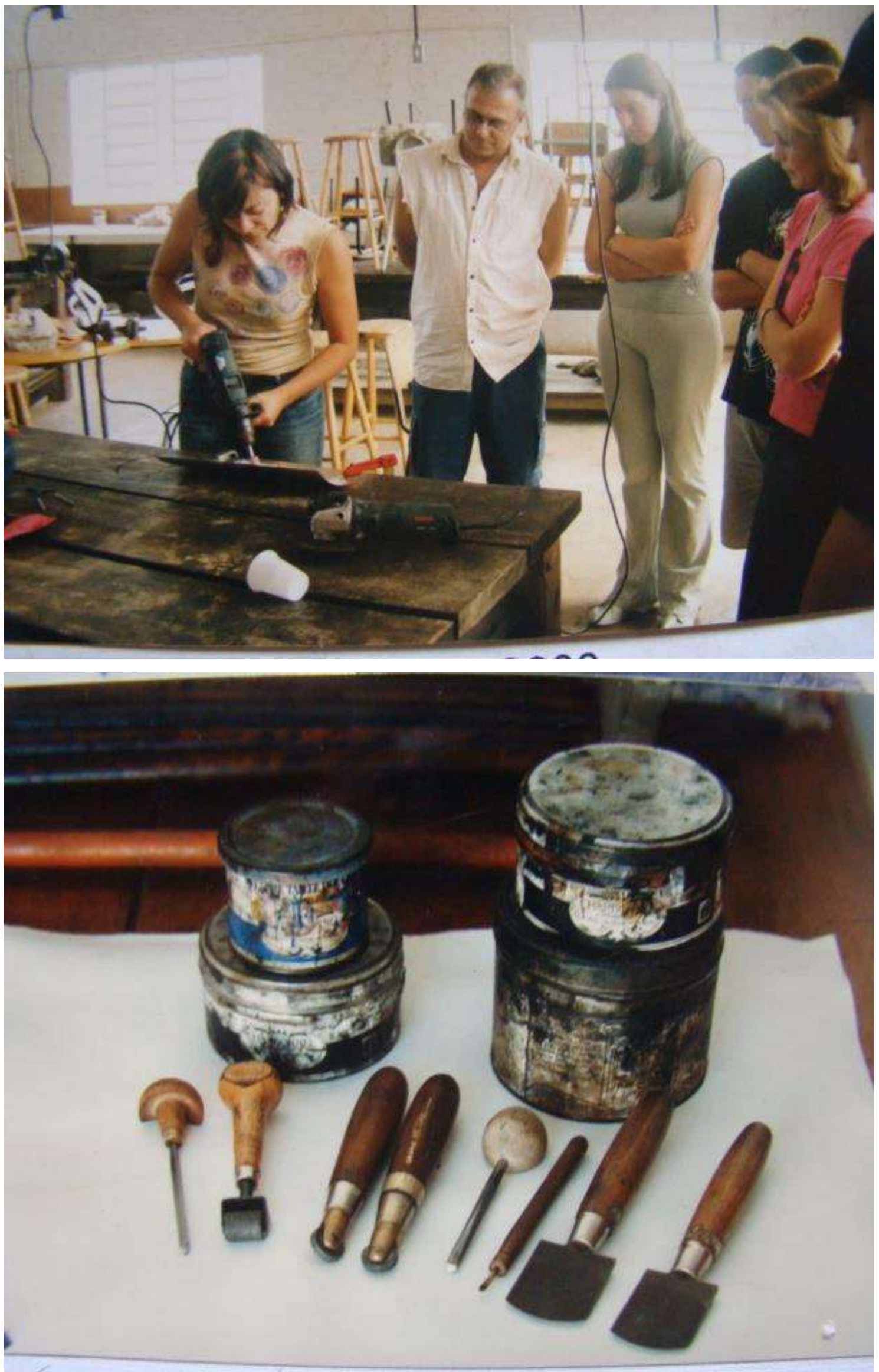